\title{
Corrosion Behavior of Aluminum in Dilute Acetic Acid Solution Simulating Cooling Water in HVDC Transmission
}

\author{
Peng Zhang ${ }^{1,3}$, Hao Zhang ${ }^{2}$, Yinsheng Xu' ${ }^{2}$,Huixi Li ${ }^{2}$, Jinxiao Liu ${ }^{3}$, Youping Fan ${ }^{1, *}$, \\ Shengping Wang ${ }^{2, *}$ \\ ${ }^{1}$ School of Electrical Engineering and Automation, Wuhan University, Wuhan 430072, China \\ ${ }^{2}$ Faculty of Material Science and Chemistry, China University of Geosciences, Wuhan 430074, China \\ ${ }^{3}$ Qujing Bureau, Extra High Voltage Power Transmission Company, China Southern Power Grid Co \\ Ltd, Qujing 655000, China \\ *E-mail: ypfan@whu.edu.cn, spwang@cug.edu.cn
}

Received: 9 November 2021 / Accepted: 27 December 2021 / Published: 2 February 2022

\begin{abstract}
The concentration, temperature effect and thermodynamic activation energy of aluminum corrosion in dilute acetic acid solution were explored by the polarization curve and the electrochemical impedance spectroscopy. With the increase of concentration and solution temperature of acetic acid solution, the corrosion resistance and charge transfer impedance of aluminum decreased. From $0 \mathrm{mM}$ to $1.00 \mathrm{mM}$ of acetic acid solution concentration, the corrosion potential, corrosion current density, anodic Tafel slope and charge transfer impedance of aluminum corrosion at $25^{\circ} \mathrm{C}$ changed from $-1.316 \mathrm{~V}, 0.207 \mu \mathrm{A} \mathrm{cm}{ }^{-2}$,

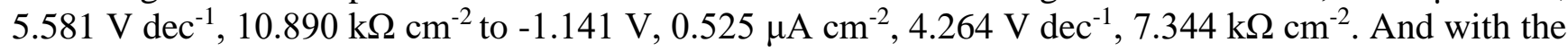
solution temperature increase from $25{ }^{\circ} \mathrm{C}$ to $55^{\circ} \mathrm{C}$, the corrosion potential, corrosion current, anodic Tafel slope and charge transfer impedance of aluminum in $0.1 \mathrm{mM}$ acetic acid solution changed from $1.248 \mathrm{~V}, 0.337 \mu \mathrm{A} \mathrm{cm} \mathrm{cm}^{-2}, 5.387 \mathrm{~V} \mathrm{dec}^{-1}, 9.590 \mathrm{k} \Omega \mathrm{cm}^{-2}$ to $-1.046 \mathrm{~V}, 1.651 \mu \mathrm{A} \mathrm{cm}{ }^{-2}, 5.031 \mathrm{~V} \mathrm{dec}^{-1}, 1.633$ $\mathrm{k} \Omega \mathrm{cm}^{-2}$. The aluminum corrosion in dilute acetic acid solution was a transition chemical reaction of four processes (diffusion $\rightarrow$ surface adsorption $\rightarrow$ surface reaction $\rightarrow$ desorption).
\end{abstract}

Keywords: aluminum, corrosion, acetic acid, radiator, high voltage direct current transmission

\section{FULL TEXT}

(C) 2022 The Authors. Published by ESG (www.electrochemsci.org). This article is an open access article distributed under the terms and conditions of the Creative Commons Attribution license (http://creativecommons.org/licenses/by/4.0/). 